\title{
On Proposing Special Issues for the Journal of Youth and Adolescence
}

\author{
Roger J. R. Levesque
}

Received: 9 October 2012/Accepted: 11 October 2012/Published online: 25 October 2012

(C) Springer Science+Business Media New York 2012

Special issues have become regular features of the Journal of Youth and Adolescence. These issues provide important fora that bring together research on cutting-edge topics as well as some that re-examine established topics from new perspectives or with more robust data. As such, they provide great value to the field, as they can energize more research in areas that would otherwise be ignored and can push the field in new directions. In a real sense, special issues put into practice the ideals of our field as they exemplify the best of empirical inquiry and scholarly inquisitiveness.

Special issues originate from several sources. Most result from invitations by the Editor, but several do not. Some have been proposed by authors who, for example, seek to publish symposia from conferences. Other issues have been proposed by scholars who wish to package together important research papers from colleagues working on related data sets or topics. Other issues have grown from researchers' interest in topics that have not been studied much; while some have emerged to address topics that already thrive in other fields but have yet to focus on adolescents. Due to that wide variety of sources, the Editor views all proposals as works in progress.

Given the increasing frequency and importance of special issues, it now seems helpful to highlight the Editor's expectations about special issues and to encourage potential editors to consider advancing their areas of research through a journal special issue. The general conclusion that potential editors hopefully will reach from this brief editorial is the Editor's keen desire to assist potential editors

R. J. R. Levesque $(\bowtie)$

Department of Criminal Justice, Indiana University,

Bloomington, IN 47405, USA

e-mail: rlevesqu@indiana.edu and authors. That desire includes considerable flexibility in the special issue topics, editors' responsibilities, and the timing of production. That flexibility, however, is couched in important limitations, all of which center on the need for all articles to make original, substantive, and important contributions to our empirical understanding of adolescence. This editorial details the important parameters that Special Issue Editors can expect as they think through whether to embark on developing a special issue.

\section{Special Issue Editors' Responsibilities}

Special Issue Editors' roles can vary considerably, but the Editor necessarily retains key roles as well. First, Special Issue Editors cannot make the ultimate editorial decision on any manuscript, as that decision lies with the Editor. Special Issue Editors also are not involved in managing the flow of manuscripts, such as sending invitations to reviewers; the Editor retains that task. Instead, Special Issue Editors identify reviewers who are willing to review (rather than simply provide names of potential reviewers) and review each submitted manuscript. It is important for them to review each manuscript for the simple reason that they need to render informed opinions when they make recommendations about whether specific manuscripts will be accepted for their special issues. Identified reviewers will be invited by the Editor, who retains the right to invite other reviewers. Thus, the Editor reviews each manuscript, assigns all reviewers, and calls the ultimate editorial decision. In addition, the Editor will send decision letters, work with revisions, and copy-edit all manuscripts so that they comport with the Journal's manuscript style and with common grammatical conventions. Thus, Special Issue Editors have the task of assisting in seeking manuscripts, 
identifying willing (and competent) reviewers, and reading each manuscript to both provide a thoughtful review and determine whether, if all goes well with the review and revision process, to accept them for their special issues.

Some Special Issue Editors may wish to publish special issue introductions. Introductions are permissible as long as they make substantive contributions above and beyond the special issue articles themselves. The Journal assumes that readers will be able to read the articles and identify their strengths and limitations, and it further assumes that all articles will note their own contributions to the study of adolescence. Thus, special issue introductions will not work if they only repeat the content of the manuscripts; introductions are justified only if they situate the articles into the relevant area of research, and do so in a substantive, original manner. The standard is undoubtedly high but not impossible to reach, as it remains a reasonable one: the standard for acceptance is the same one used for regular submissions, which is that they make an independent, substantive and original contribution (see, as excellent examples of special issue introductions, Horn et al. 2009; Lerner et al. 2010).

\section{Proposals and Typical Concerns}

Recognizing that proposals are unique to the talents of the special issue proponents, the Editor remains flexible in considering what Special Issue Editors submit. Still, effective proposals tend to do the following:

- Describe the nature of the topic. Please give the Editor a sense of the topic but keep in mind that there is no need for an extended analysis, as the Editor easily can surmise the importance and potential fruitfulness of the topic.

- List potential authors. If available, the list should include an explanation of the authors' openness or readiness to submit. If calls for proposals are warranted, the Editor will work with the Special Issue Editors to craft effective calls, although the Editor still expects the Special Issue Editors to distribute calls and use their own professional connections to drum up appropriate submissions.

- Plan for external reviewers. Given the potential narrowness of special issues, it is important to articulate how reviewers will be identified and commit to reviewing. Since the journal is multidisciplinary, there should be a balance between experts on the topic of the manuscript and generalists who can give the manuscript a reading in light of the need to reach a broad audience. Potential authors can serve as reviewers, as they will not be competing for space due to the journal's not having space limitations.
- Articulate special requests. This component is important to avoid future misunderstandings. Special requests tend to be easily accommodated, as the typical ones relate to timing or space limitations. The Journal publishes twelve issues per year, and remains the largest in the field, so we have neither timing nor space limitations. The lack of space limitations is important to emphasize, as it allows us to publish all appropriate manuscripts that fall within the Journal's mission. We generally can move as quickly and slowly as the editors wish, and the editors generally also can aim for as large an issue as they wish (also see below).

- Note the appropriateness of the Special Issue Editors. Proposals that are not initiated by the Editor should have a section that briefly details how the Special Issue Editors are up to the task of successfully shepherding an exceptionally strong special issue. This is particularly the case for emerging scholars (see below) or researchers who have not worked with the Editor, either as authors or reviewers. If multiple editors propose to work together, please do clarify envisioned, respective roles (e.g., how different tasks will be divided).

- Recognize the Journal's mission. Not all topics and manuscripts that happen to relate to the adolescent period fall within the journal's mission. For example, manuscripts need to take a developmental approach and engage adolescent research, brief reports tend not to survive external review, reviews of the literature need to make independent contributions, mixed methods analyses must use methods that stand on their own, individual studies of multi-study manuscripts also must stand on their own, and the journal style will be followed regardless of who submits a manuscript.

Importantly, the above points should not be imbued with talismanic qualities. They are provided as guidelines and topics that Special Issue Editors may wish to consider as the Editor likely will be interested in knowing whether they have been taken into account.

\section{The Review Process}

The review process for proposals themselves is quite straightforward. Proposals are accepted if they address important areas of adolescent development and if they will attract authors who will make original and significant contributions to the study of adolescence. Thus, it helps if the Special Issue Editors have identified potential authors and if they can make the case that there will be enough manuscripts to fill a journal special issue (typically 10-12 manuscripts; but there is considerable flexibility on this point, including the possibility of ending up with a special 
section of an issue or moving to a double issue). The ultimate goal is to give the Editor a sense that there will be interest among potential authors, a reasonable standard to the extent that a lack of interest among authors likely will translate into little interest among readers.

The review process for the individual manuscripts also is straightforward. The minimum standard is that the Editor needs to have at least two "blind," Ph.D. level reviewers who provide careful reviews and who do not counsel rejection. As noted earlier, all manuscripts must be reviewed, and all manuscripts are subject to the Editor's final approval. In addition, since the Special Issue Editors have considerable expertise in the relevant area, the Editor grants them somewhat wide latitude in developing the issue that they proposed. If they submit their own manuscripts and if the manuscripts fall within the journal's mission, the Editor takes the responsibility to assign reviewers. But, as with all manuscripts, the Journal has adopted the policy that the Editor welcomes suggestions for reviewers. The ultimate goal is to have thoughtful reviews useful for not only making an editorial decision but also crafting stronger manuscripts. As a result, all manuscripts tend to have between 3 and 5 reviews as well as a detailed review from the Editor, if the Editor requests revisions. Despite the minimum standard articulated above, then, the Editor expects all manuscripts to undergo a rigorous review and effective engagement in the marketplace of ideas.

\section{Scheduling}

Like authors, Special Issue Editors often are interested in the special issue's schedule of production. The Editor will work with any schedule. Having said that, the Editor expects quick reviews of manuscripts (within 3 weeks) and especially quick responses to review requests. In addition, the special issue cannot go to press until all manuscripts have been accepted for publication. Thus, the formal release (hard copy print) of the special issue itself could be difficult to judge, as it depends on the cooperation of editors, reviewers and authors. Still, the publisher's staff appropriately enjoys the reputation for being quite quick in processing manuscripts and can move them remarkably quickly to proof stage and to publication. Again, the Journal publishes many issues per year and is quite flexible in terms of releasing special issues. Also again, much remains within the control of the Special Issue Editors as they seek to make the strongest possible special issue that will maximize the impact that the authors' work rightly deserves.

\section{Emerging Scholars Welcomed}

Emerging scholars, including advanced graduate students, may serve as Special Issue Editors. This possibility results from the nature of the review process noted above; all issues rely on "blind," doctoral level peer reviewers. Although a possibility, it must be noted that taking the lead on a special issue is not an easy task, as it demands an important time commitment and requires connections to the field to have both authors submit and reviewers review. Still, nothing precludes emerging scholars from taking the lead if they can convince the Editor that they will be able to fill their role judiciously. The chances of making a convincing case certainly increases if emerging scholars pair with established leaders in the field who can assist in ensuring that the development of the special issue will comport with the journal's mission, which includes being responsive, supportive and kind in the execution of responsibilities to reviewers, authors, readers, and the field of developmental science relating to adolescents.

\section{References}

Horn, S. S., Kosciw, J. G., \& Russell, S. T. (2009). New research on lesbian, gay, bisexual, and transgender youth: Studying lives in context [editorial]. Journal of Youth and Adolescence, 38, 863-866. doi:10.1007/s10964-009-9420-1.

Lerner, R. M., von Eye, A., Lerner, J., Lewin-Bizan, S., \& Bowers, E. (2010). Special issue introduction: The meaning and measurement of thriving: A view of the issues [editorial]. Journal of Youth and Adolescence, 39, 707-719. doi:10.1007/s10964010-9531-8.

\section{Author Biography}

Roger J. R. Levesque Professor of Criminal Justice at Indiana University, serves as Editor of the Journal of Youth and Adolescence. 